\title{
Performance of Noise Map Service Working in Cloud Computing Environment
}

\author{
Karolina MARCINIUK ${ }^{(1)}$, Maciej SZCZODRAK ${ }^{(1)}$, Bożena $\operatorname{KOSTEK}^{(2)}$ \\ (1) Multimedia Systems Department \\ (2) Audio Acoustics Laboratory \\ Faculty of Electronics, Telecommunications and Informatics \\ Gdańsk University of Technology \\ Narutowicza 11/12, 80-233 Gdańsk, Poland; e-mail: karmarci@sound.eti.pg.gda.pl
}

(received March 11, 2016; accepted April 5, 2016)

\begin{abstract}
In the paper, a noise map service designated for the user interested in environmental noise is presented. Noise prediction algorithm and source model, developed for creating acoustic maps, are working in the cloud computing environment. In the study, issues related to the noise modelling of sound propagation in urban spaces are discussed with a particular focus on traffic noise. Examples of results obtained through a web application created for that purpose are shown. In addition, these are compared to results obtained from the commercial software simulations based on two road noise prediction models. Moreover, the computing performance of the developed application is investigated and analyzed. In the paper, a flowchart simulating the operation of the noise web-based service is presented showing that the created application is easy to use even for people with little experience in computer technology.
\end{abstract}

Keywords: noise maps; dynamic noise maps; sound propagation; environmental noise; web applications; cloud computing.

\section{Introduction}

Noise is commonly defined as "unwanted sound", a more precise description refers to the audible sound that causes disturbance, impairment or health damage (EEA, 2010). Because of the growing noise pollution an increasing number of people suffer from hearing loss at various levels. The high sound level does not only affect the organ of hearing, damages the nervous system but may cause cognitive impairment (EEA, 2010). Research conducted in Denmark showed that $19 \%$ of strokes among people over 65 years of age are due to the road traffic noise (SøRENSEN, 2010). Fortunately, social awareness of the degrading effect of noise on human health and productivity is increasing (EEA, 2010). The noise preventing actions are enforced not only through legal regulations but also through initiatives of the scientific activity (FHWA, 2010; GARG et al., 2015; BATKO, BALPyrcz, 2014; KŁaczyŃSKi, WszoteK, 2014; KomPaŁa, LipowCZan, 2007; Kucharski, 2007; ShehaP et al., 2016) or carried out by smaller groups of interest.
The end of the previous decade was characterized by a significant increase in the development and usage of software as a service implementation provided over the Internet. At the time when the computer simulations are a fully accepted method of conducting experiments, a single data file can weigh more than $100 \mathrm{~GB}$ and a simple acoustic simulation of a concert hall can take up 3 to 10 hours on a modern PC, the access to the data centers and computing resources becomes a necessity. The boost in the number of supercomputers and the interest in them expressed by the science centers initiated the trend of cloud computing. It should be noted that this overarching term affects all areas of modern computing.

With the cooperation between all academic supercomputing centers (Gdańsk, Wrocław, Warszawa, Poznań, Kraków), an integrated network infrastructure called PL-Grid was established. Thanks to the grid technology, the integration of computing resources, data storage systems, unique scientific instruments, applications and data was accomplished. An important factor is the visualization of resources and methodol- 
ogy for a service-oriented architecture (SOA), through which it is possible to create a system of services for e-science (Ministry of Science and Higher Education, 2007).

Noise Maps, one of the services available in the PLGrid platform developed in 2014 by the team of scientists from Multimedia System Departments at Gdansk University of Technology, is devoted to calculating the acoustic field distribution. In the paper, a flowchart simulating the operation of the noise web-based service is presented. The computing performance of the application developed is investigated and analyzed.

\section{Noise indicators}

The noise maps are developed for the purpose of analysis and noise pollution preventing. Noise maps in most cases are prepared by numerical calculations. Their accuracy depends on quality of the input data (traffic flow), complexity of the building geometry and terrain elevation (WETLESEN, 2013).

Typical strategic noise maps have to be updated every four years showing the $L_{d e n}$ indicator, the average sound level during a year. The measurements are performed in specific time line of a year arbitrarily approved as a statistical one day. This indicator considers the degree of annoyance for different times of the day (Eq. (1)), where $L_{d}$ is a long-term, A-weighted sound average sound level consistent with the definition given in ISO 1996-21987, determined for all day over the year, similarly $L_{e}$ is the equivalent sound pressure level of the evening and $L_{n}$ refers to the night time. The daytime refers to the time period between 7.0 and 19.0, the evening is defined as a period between 19.0 and 23.0 and the night between 23.00 and 7.00 (European Directive, 2002):

$L_{d e n}=10 \log \frac{1}{24}\left(12 \cdot 10^{\frac{L_{d}}{10}}+4 \cdot 10^{\frac{L_{e+5}}{10}}+8 \cdot 10^{\frac{L_{n}+10}{10}}\right)$.

The acceptable noise levels in cities during the day are in the range of 50-65 $\mathrm{dB}$, depending on the type and function of buildings in the neighborhood and it should be lower by $5 \mathrm{~dB}$ for the night time (Ministry of the Environment, 2007).

An acoustic climate of the city, or a specific area varies in noise intensity of sources during the chosen periods of the year, week and day. For example:

- some part of the roads can be more frequented at the weekends,

- not every airport has a balanced timetable (e.g. military training airport),

- some cities have regular mass events significantly affecting the level of noise, some of them take place for more than three days,

- noise maps do not take into considerations maximum sound levels during a day/hour, which may be different over a period of the daytime due to constructions works,

- noise models do not take into consideration special acoustic effect such as sound of brakes, emergency vehicles (WETLESEN, 2013).

The statements presented above may often be a decisive factor for local authorities to develop a continuous noise monitoring system with publicly available results of measurements (MiODUSZEWSKI et al., 2011; City of Gdansk Authorities, 2016). Moreover, the strategic noise maps present the sounds emitted by a particular sources on individual layers. A presentation summarizing the noise levels generated by all those sources may prove to be more accessible for the public audience.

Due to the immense progress in technology, the noise monitoring stations can now be smaller, costeffective, and centrally controlled (SzczODRAK et al., 2008). Sensors can be triggered by a predefined sound event such as a gunshot or a scream (LOPATKA et al., 2011) or just carry out continuous measurement limiting data transmission to the specific indicators, e.g. $L_{A e q 1 h}, L_{n}, L_{e q}$, etc. Other significant variables are temperature and humidity.

\section{Cloud computing and PL-Grid infrastructure}

The key concept behind cloud computing is the remote access to computing resources physically unavailable on personal computers. The resources are often placed in locations remote to the client (over the Internet, optical network), hence the time and financial resources are consumed in a more efficient manner. The software is centrally managed and the access is controlled by the queuing systems.

Most of the supercomputers operate on UNIXbased systems and the applications are dedicated to the needs of a narrow group of scientific specialists. The Noise Maps application developed in the PL-Grid infrastructure opened a new set of noise mapping use cases for a wide group of acoustic consultants or public employees. The front-end web interface of the application is user-friendly and accessible for a wide audience of nonspecialists end-users.

As a part of the PL-Grid platform, each user has access to free of charge half-year renewable personal grant. It includes 1,000 normalized hours of calculation, and $40 \mathrm{~GB}$ of storage memory. It is active in all five supercomputer centers in Poland: Cyfronet, WCSS, PSNC, ICM UW and TASK. At any time, the user can apply for a dedicated grant, constructed according to the required computational resources.

A so-called normalized hour is used for calculation of the total resource usage and is related to the number of cluster processor cores engaged in computations and time period of their operation. Total consumption of resources for a particular task is the product of 
the number of used cores and the elapsed calculation time. Therefore, it would take 240 normalized hours to run two tasks performed on 60 cores for the period of 2 hours.

The presented application implemented as a service in PL-Grid infrastructure is called Noise Maps. The application allows for one hour period daily noise analysis in the localization provided by the user. The access to the service is available for users who registered an account in the PL-Grid portal. The interface provides two alternatives of the user interaction: advanced (through modification of detailed configuration scripts) and simple, based on modification of basic parameter values in the graphical UI forms. The workflow is shown in Fig. 1. Dynamic and static parameter types can be distinguished. The dynamic type parameters include such data as noise source parameters, particularly the number of vehicles per hour, and speed for each road section. An example of a static type parameter is the building absorption coefficient. Geometric description of roads and buildings is provided in a popular Geographic Information System (GIS) Shapefile format. The data can easily be modified or created by the user through a free GIS software.

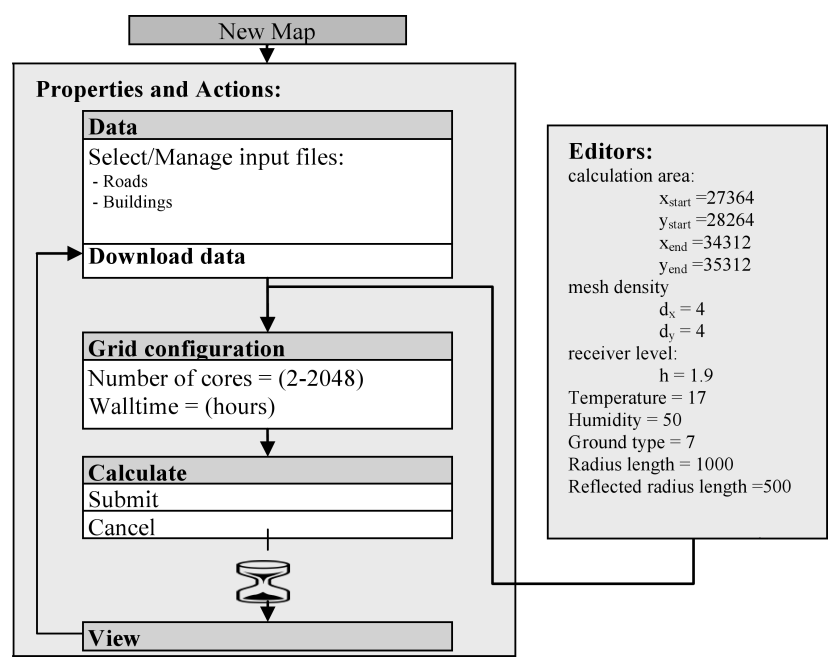

Fig. 1. Diagram of calculation process in the "Noise Maps" service.

\section{Investigated traffic noise models}

The traffic noise has a major share in the overall noise level in cities. The work on road noise modelling dates as far as over half a century ago, thus in standard cases the predictions are very accurate. But with the progressive complexity of the surrounding areas, more computing resources are needed.

A typical algorithm needs information about the traffic flow, the ratio of heavy to light vehicles, road parameters and the weather conditions. In this paper, three traffic noise models (TNMs) were briefly described and then compared. The first one is a cloud operated Noise Maps on the PL-Grid (including Harmonoise model), the other two are CoRTN (prepared in the United Kingdom) and NMPB-Routes (French model).

The CoRTN noise model consists in several parts. Initially, the road is divided into smaller segments with the noise variations less than $2 \mathrm{dBA}$. Then, the basic noise levels are calculated at a reference distance of $10 \mathrm{~m}$ away from the nearside carriageway edge. The value depends on the time of observation (hourly $L_{101 H}$ or 18 hour $L_{10}$ ), vehicle flow, speed, percent of the heavy vehicles, gradient of the road, and a road surface. Lastly, the part three takes into account propagation properties of the nearest area (view angle, reflections and absorptions). To obtain the total noise level in a specific point, all the segments need to be summed up (QUARTIERI et al., 2009).

NMPB-Routes is a French standard, recommended by the European Union in directive 2002/49/EC for countries that did not develop their national models. The method is similar to the ray tracing model, the accuracy depends on the number of paths formed between the source and the receiver, and the number of allowed reflections. The method takes into consideration the standard metrological conditions. The attenuation are split into atmospheric absorption, boundary attenuations (propagation conditions and ground effect) and diffraction. The main noise levels, similarly to the CoRTN, depend on the traffic and the ratio of heavy vehicles.

The Harmonoise model was intended to provide a basis for a new standard European model. A method of point to point propagation is used therefore linear sources should be segmented (SALOMONs et al., 2011). The ray tracing technique implemented within the PL-Grid Noise Maps service provides point sources both direct and reflected by obstacles According to Harmonoise, the source model consists of vehicle and traffic models. The sound power of a single vehicle is calculated on the basis of velocity as one of the input parameters. The traffic model is utilized to combine noise emission of numerous single vehicles according to traffic statistics. The output of the source model is the sound power per one meter length of a linear source. Road vehicles are classified into five categories, each represented by two sources at different heights. The concept of sound propagation paths describing schematic lines of acoustic wave between a single point source and a receiver is utilized in the propagation model. The total noise level at the particular point is determined by the sum of all contributing point sources found in propagation paths.

Although the comparison of the methods was often carried out in the literature (QUARTIERI et al., 2009; GUARNACCIA, 2013), in this paper the values obtained by the two TNM standards and the model prepared to work in the cloud computing environment, were juxta- 
posed with the outcomes of the measurements collected by noise monitoring station.

\section{Experimental results}

\subsection{Models and measurement comparison}

The calculation of noise level distribution for the analyzed region was performed using the CadnaA software and the discussed PL-Grid application. In the first part of experiments, we compared the results obtained for the location A $\left(54^{\circ} 22^{\prime} 14.4^{\prime \prime} \mathrm{N}\right.$, $\left.18^{\circ} 36^{\prime} 37.7^{\prime \prime} \mathrm{E}\right)$, and $\mathrm{B}\left(54^{\circ} 22^{\prime} 34.7^{\prime \prime} \mathrm{N} 18^{\circ} 36^{\prime} 53.5^{\prime \prime} \mathrm{E}\right)$ which is equivalent to the position of the measuring station installed by the City of Gdansk (Monitoring). The receptor (point $\mathrm{A}$ ) is located on the facade of the building located at a distance of $4 \mathrm{~m}$ from the road with the average intensity of 1040 vehicles for the daytime and at a distance of $50 \mathrm{~m}$ from the intersection with traffic lights. The results for the different times of the day and the total level $L_{d e n}$ are shown in Table 1 .

For the results obtained for each noise indicator, the coefficient of variation was determined as the ratio of standard deviation and arithmetic average of the collected measurements. As can be observed, the levels obtained using Noise Maps are more accurate in reflecting the real level of noise in the tested area. Significant differences between theoretically predicted levels and the measured one are particularly visible for the night time. It can be an effect of various sound events that significantly affect the well-being of inhabitants. The prediction results obtained by Noise Maps service and two additional models available in CadnaA software are presented in Table 1.

For the point located closer to the main streets and crossroads (point B), the results for individual models show much smaller discrepancy with regard to the point A. Similarly to the first point, the largest disproportions are noticed in the night time.

Observed differences between calculated and measured noise levels in the night time may be caused by the increase in road traffic during the last few years. The road traffic data used in simulations originate from the input data prepared for strategic noise map in 2008. During recent 8 years, the night traffic volume in the main street increased by $30 \%$ on average.

\subsection{Computation cost}

The second part of the experiments concerned the calculation of the noise map of the $0.9 \mathrm{~km}^{2}$ area of Campus of the Technical University of Gdansk. We present the results of the measurements of computation time of the whole map for the grid raster of $4 \times 4 \mathrm{~m}$, calculated on the supercomputer. "Noise Maps" grid service enables a user to select the number of processor cores involved in the calculation as well as the supercomputing centre. In TASK (Tri-City Academic Computer Network Center), the available cluster consists of 192 nodes (each with two six-core Intel Xeon $2.27 \mathrm{GHz}$ and $16 \mathrm{~GB}$ of RAM). The computational power of the entire cluster is 20.9 TFlops. The user can thus select the number of cores in the range between 2 and 2304. The computation time and, indirectly, amount of the engaged computer cluster power is relevant for the calculation of the dynamic noise map and the requirement of its frequent update.

The size of the area and the grid density define the number of points to be considered in the simulations. In the discussed case, for the area of approximately $980 \mathrm{~m}$ per $910 \mathrm{~m}$, using the grid raster of $4 \times 4 \mathrm{~m}$, 56726 points were identified for calculation. Table 2 shows computation performance expressed in points per second in relation to the amount of used resources (number of cores).

Table 1. Sound levels obtained by the three calculation methods and the results of the measurement for A and B points.

\begin{tabular}{|l|c|c|c|c|c|c|c|c|}
\hline & \multicolumn{4}{|c|}{ Point A } & \multicolumn{4}{c|}{ Point B } \\
\hline Noise indicator & $L_{\text {den }}$ & $L_{d}$ & $L_{e}$ & $L_{n}$ & $L_{d e n}$ & $L_{d}$ & $L_{e}$ & $L_{n}$ \\
\hline NMPB-Routes 96 [dB] & 67.8 & 67.0 & 65.2 & 57.4 & 73.3 & 72.7 & 71.2 & 62.1 \\
\hline CoRTN [dB] & 70.5 & 69.6 & 67.8 & 60.0 & 73.8 & 73.2 & 71.1 & 67.8 \\
\hline Noise Maps on PL-Grid [dB] & 74.0 & 73.2 & 71.3 & 63.5 & 75.7 & 73.1 & 71.6 & 62.6 \\
\hline In-situ measurements [dB] & 76.5 & 74.1 & 73.4 & 67.9 & 75.8 & 72.6 & 71.1 & 68.2 \\
\hline The variation coefficient [\%] & $\mathbf{6}$ & $\mathbf{5}$ & $\mathbf{6}$ & $\mathbf{8}$ & $\mathbf{1 . 7}$ & $\mathbf{0 . 4}$ & $\mathbf{0 . 3}$ & $\mathbf{5}$ \\
\hline Max. difference [dB] & $\mathbf{9 . 7}$ & $\mathbf{8 . 0}$ & $\mathbf{9 . 3}$ & $\mathbf{1 1 . 7}$ & $\mathbf{2 . 5}$ & $\mathbf{0 . 6}$ & $\mathbf{0 . 5}$ & $\mathbf{6 . 1}$ \\
\hline
\end{tabular}

Table 2. Noise maps calculation performance (points/s) related to the number of exploited cores.

\begin{tabular}{|l|c|c|c|c|c|c|c|c|}
\hline Amount of cores & 24 & 36 & 48 & 60 & 72 & 84 & 96 & 180 \\
\hline Performance [points/s] & 2.65 & 4.07 & 5.39 & 6.81 & 8.23 & 9.68 & 11.03 & 20.32 \\
\hline
\end{tabular}


Due to the nature of the supercomputer grid queuing system, tasks that require more resources are occasionally assigned a lower priority. Figure 2 depicts the relation between the calculation time and the number of cores used. Two cases are presented: first, time between the task submission and calculation end ("total time of service"), and second, time between the calculation start and calculation end ("computing time").

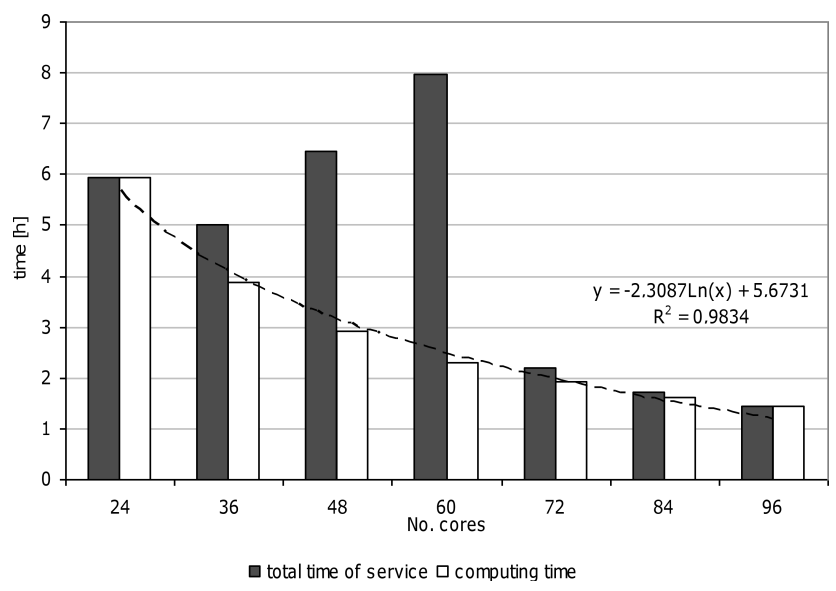

Fig. 2. Total time of service and computing time for a specific core amount.

The detailed discussion on computation performance is presented in the authors' earlier work (MARciniuk et al., 2015; Szczodrak et al., 2014).

\section{Summary}

We presented a modern, cloud computing based service for calculation of the noise maps. It provides an access to efficient computational resources not only to the specialists in the domain of acoustics but also to all people interested in noise pollution abatement.

The results obtained using the described grid service are consistent with the results from the carried out measurements. A small discrepancy between the simulation using the service developed and measurement results is due to the fact that road traffic data provided came from 2008 when data for strategic noise maps were gathered.

In the future, the development of the interface could be aimed at providing information about the way the algorithm settings as well as noise indicators parameters change the simulation result. Moreover, a tutorial including basic knowledge about noise propagation could be prepared to be easily accessed by the users. Then, the presented grid application could evolve into commonly available website and fulfill the educational role for the society on the noise harmful impact.

Due to the nature of the supercomputer grid queuing system, tasks that require more resources are oc- casionally assigned a lower priority. This may result in a longer overall time needed to accomplish a task, which was also shown in the paper. Overall, it may be said that the dynamic noise map, updated frequently, is still not an easily attainable goal.

\section{Acknowledgments}

This research was partially supported by the Polish National Centre for Research and Development within the grant No. OT4-4B/AGH-PG-WSTKT. The authors are grateful to PL-Grid Infrastructure resources for enabling the investigations carried out within this research study.

\section{References}

1. Batko W., Bal-Pyrcz R. (2007), Analysis of stochastic acoustical hazards in environment, Archives of Acoustics, 32, 4 (Supplement), 235-245.

2. City of Gdansk Authorities (2016), [in Polish] Portal Mapy Akustycznej i Monitoringu Hałasu Miasta Gdańska,

http://mapaakustyczna.gdansk.gda.pl/GdanskMakus (accessed March 2016).

3. EEA (European Environment Agency) Technical report (2010), No. 11, Good practice guide on noise exposure and potential health effects, Copenhagen, ISSN $1725-2237$.

4. European Directive 2002/49/EC (2002), European Parliament and Council of 25/06/2002 Relating to the Assessment and Management of Environmental Noise".

5. FHWA (Federal Highway Administration), Highway Traffic and Construction Noise - Regulation and Guidance, http://www.fhwa.dot.gov/environment/noise/ regulations_and_guidance/ (accessed March 2016).

6. Garg N., Vishesh Maji S. (2015), Fuzzy TOPSIS Approach in Selection of Optimal Noise Barrier for Traffic Noise Abatement, Archives of Acoustics, 40, 4, 453-467, DOI: 10.1515/aoa-2015-0045.

7. Guarnaccia C. (2013), Advanced Tools for Traffic Noise Modelling and Prediction, WSEAS Transactions on Systems, 12, 2.

8. KŁaczyński M., WszoŁek T. (2014), Acoustic Study of REpower MM92 Wind Turbines During Exploitation, Archives of Acoustics, 39, 1, 3-10, DOI: 10.2478/aoa-2014-0001.

9. Kompata J., LipowCZAN A. (2007), Efficiency of Noise Reduction by a Road Speed Bump, Archives of Acoustics, 32, 3, 631-642.

10. Kucharski R. (2007), Complex Noise Indicator for Noise Mapping Based on the EU Working Groups' and Polish Results of the Annoyance Investigations, Archives of Acoustics, 32, 2, 293-302.

11. Łopatka K., Kotus J., Czyżewski A. (2011), Application of Vector Sensors to Acoustic Surveillance of 
a Public Interior Space, Archives of Acoustics, 36, 4, 851-860.

12. Marciniuk K., Szczodrak M., Kostek B. (2015), Wyznaczanie map hatasu z wykorzystaniem chmury obliczeniowej [in Polish], 16th International Symposium on Sound Engineering and Tonmeistering, Wrocław, 8-10.10.2015.

13. Ministry of Science and Higher Education [in Polish], Program Rozwoju Infrastruktury Informatycznej Nauki na lata 2007-2013, Ministerstwo Nauki i Szkolnictwa Wyższego, 28 czerwca 2007 r.

14. Ministry of the Environemnt [in Polish], Dz.U. 07.120.826 Rozporządzenie Ministra Środowiska z dnia 14 czerwca 2007 r. w sprawie dopuszczalnych poziomów hałasu w środowisku.

15. Mioduszewski P., Ejsmont J.A., Grabowski J., KARPINSKI D. (2011), Noise map validation by continuous noise monitoring, Applied Acoustics, 72, 8, 582589.

16. Quartieri J., Mastorakis N.E., Iannone G., Guarnaccia C., D'Ambrosio S., Troisi A., Lenza T.L.L. (2009), A Review of Traffic Noise Predictive Models, Recent Advances in Applied and Theoretical Mechanics, 5th WSEAS International Conference on Applied and Theoretical Mechanics (MECHA-
NICS '09) Puerto De La Cruz, Tenerife, Canary Islands, Spain December 14-16, 72-80.

17. Salomons E., Van Maercke D., Defrance J., De Roo F. (2011), The Harmonoise sound propagation model, Acta Acustica united with Acustica, 97, 62-74.

18. SøRensen M. (2010), Road traffic noise and stroke: a prospective cohort study, European Heart Journal, http://cordis.europa.eu/news/rcn/33064_en.pdf.

19. Szczodrak, M., Czyżewski, A., Kotus, J. (2008), Investigation of the Road Noise Source Employing an Automatic Noise Monitoring Station, Archives of Acoustics, 33, 4 (Supplement), 77-83.

20. Szczodrak M., Czyżewski A., Kotus J., KosTEK B. (2014), Frequently updated noise threat maps created with use of supercomputing grid, Noise Mapping, 1, 1, 32-39.

21. Shehap H., Shawky A., El-Basheer T.M. (2016), Study and Assessment of Low Frequency Noise in Occupational Settings, Archives of Acoustics, 41, 1, 151160, DOI: 10.1515/aoa-2016-0015.

22. Wetlesen T. (2013), Cloud computing for noise monitoring, [in:] INTER-NOISE and NOISE-CON Congress and Conference Proceedings, Institute of Noise Control Engineering, pp. 2987-2982. 